\title{
The Indispensability and the Perplexities of Youth Work in the Lebanese Context
}

\author{
By Nicholas Rossis*
}

This paper investigates through a situational and empirical analysis the inescapable paradox regarding the absolute necessity of youth work in Lebanon and the dilemmas that hinder its productive and untrammelled function. Although Lebanon is not typically associated with world hunger, extreme poverty and reliance on humanitarian aid for the survival of parts of its population, youth work is the ultimate nexus that through a unique sense of balance bridges the usual community support activities with humanitarian relief. Youth work in the Lebanese context is a multifaceted activity and often the country seems to be totally reliant on such domestic and international actions in order to safeguard the welfare, the education, the recreation and the social support of children, adolescents and young adults. Despite the continuous endeavours for streamlining and for the adoption of a more comprehensive and less bureaucratic regulatory framework, the challenges that youth work in Lebanon faces are endemic and deeply embedded into the diverse social and cultural values of the country, as youth work has also the capacity to mirror the political, economic and social outline of the entire Levant. This article establishes youth work as an additional analytical tool for understanding the challenges, the malignancies, the dependencies and the urgent exigencies of the Lebanese social and political mosaic.

Keywords: confessions, corruption, cultural identity, humanitarian aid, Lebanon, youth work, social services, social welfare

\section{Introduction}

Youth work in Lebanon plays an exceptionally significant role, as it also compensates for the lack of social services and infrastructure in the country. The enhanced responsibilities of the civil society in Lebanon elevate the status of the manifold Non-Governmental Organisations (NGOs), as the state apparatus reluctantly recognises its insufficiencies and sub-contracts those organisations for the provision of basic social services. Youth work NGOS are no exception in light of this approach, however the political instability, corruption and the uninterrupted sectarian strife prey on their sustainable operation, without presenting any alternatives.

This paper investigates through a situational and empirical analysis the inescapable paradox regarding the absolute necessity of youth work in Lebanon and the dilemmas that hinder its productive and untrammelled function. Youth work in the Lebanese context is a multifaceted activity and often the country seems to be totally reliant on such domestic and international actions in order to safeguard the welfare, the education, the recreation and the social support of children, adolescents and young adults. Despite the continuous endeavours for

${ }^{*}$ Lecturer, Arcadia University, USA. 
streamlining and for the adoption of a rather more comprehensive and less bureaucratic regulatory framework, the challenges that youth work in Lebanon faces are endemic and deeply embedded into the diverse social and cultural values of the country. Youth work in Lebanon is rarely featured in high politics debates; however it often becomes an effective political instrument with ulterior motives and above all it broadly and painstakingly mirrors the political, economic and social outline of the entire Levant.

The primary aim of this paper is to elucidate the constant need of youth work within the Lebanese context and to project the malignancies, the inadequacies and the cultural attributes that impinge on youth work and comprise this complicated relationship. Therefore, the basic research questions of this paper focus on why youth work is so necessary and on what makes youth work so convoluted in Lebanon. The crux of the matter is that youth work often appears to stand on a problematic equilibrium between its demanding duty to exist and the issues that affect its potential for sustainability and development. For that reason, the paper also sheds light on the impact of this catch-22 situation on the future of youth work in the country.

\section{Methodology}

The foundation of the analysis of this paper follows the trajectory of youth work in Lebanon from June 2015 to June 2017. A great deal of preliminary field work had been conducted as part of a Regional Capacity Building Support Unit (RCBS) for the Euromed Youth Programme IV publication on youth work in Lebanon and its cultural identities, which offered the unprecedented chance to map out throughout the country the most significant and impactful youth work initiatives. The present research has been benefited by the previous establishment of multiple starting or contact points in various geographical areas of the country, which allowed the observance of the progression and the growth of youth work efforts in regions with varied religious backgrounds, diverse social stratification and completely different requirements.

The data collected through the observations from the field research, along with testimonials and the semi-structured interviews with government officials (including party representatives from the Ministry of Education and the Ministry of Sports and Youth), as well as university professors from Notre Dame University, NGO officials, youth workers and beneficiaries provided the compelling evidence regarding the need, the impact and the probable complexities impinging on youth work in Lebanon. The analysis is based on an original survey throughout the country during the field research, allowing to this paper to cover a broad spatial range for random sampling and it was also supported by an open-ended questionnaire. Those who were unable to answer face-to-face, had the chance to complete an online questionnaire. However, the initial questionnaires proved to be inadequate to the needs of the research; therefore most of the respondents have been re-visited or re-contacted for follow-up questions and clarifications. The major problematic of the open-ended questionnaires was the 
tendency of the respondents to omit answering specific questions and the subsequent impracticality to code and quantify the responses of the 114 participants. As a result, this paper analysed all the answers for repetition of particular words and trends in order capture the overall predilection and opinion of the respondents in relevance to the research questions. A secondary problematic was the sensitive nature of many questions, especially of those related to corruption, as well as of those related to the social inclusion of all the confessions and particularly of those related to the role of women in youth work, as the respondents were prone to bias and insularity and few were even concerned about their personal safety. Additionally, future research should explore more systematically the qualitative angle of youth workers and the youth work beneficiaries and explore the pragmatic output of many NGOs in terms of vocational training.

In terms of the secondary sources, the overall scholarship around the issues of youth work within the Lebanese context appears to be disjointed and relatively limited, as the majority of the material stems from institutional reports for policy making purposes and pamphlets compiled by various NGOs operating in the field of youth work domestically or in Europe.

This article establishes youth work as an additional analytical tool for understanding the challenges, the malignancies, the dependencies and the urgent exigencies of the Lebanese social and political mosaic.

\section{Youth Work and the Lebanese Perspective}

Perhaps one of the most troubling issues when researching about Lebanon is the lack of reliable statistical data regarding its population, as an official census has not been conducted since 1932. The purely political rationale behind this omission relates to the dangerous transformations and tensions that a new census will bring on the parliament and the balance of power in the country (The Economist 2016). The members of the Lebanese Parliament are elected through a confessional system that proportionally allocates the seats through specific quotas from all the constitutionally recognized religious groups (Rigby 2000).

Recent data through the vote registries have only confirmed the widespread perceptions of the shift in the sectarian proportions (The Economist 2016), yet they are not a reliable enough or an indicative source regarding the size of youth in the country, as the mercurial election process due to vote buying is never immune to corruption (Wickberg 2012). In Lebanon an individual from 15 up to 29 years of age may be considered as youth. According to the United Nations (2017) the percentage of "youth", within the country of the almost 6 million inhabitants, ranges between $27 \%$ to $32 \%$ as all the people under 25 years old represent $42 \%$ of the Lebanese population (World Population Prospects 2017). However, due to the influx of more than 1.25 million refugees from Syria since 2011 and the more than 500.000 registered Palestinian refugees who live in the country since 1948, coupled with those who unofficially live inside and outside of the refugee camps, it is impossible to obtain an accurate population outlook (UNHCR 2016). 
However, the accuracy of those numbers is disputed by the Lebanese Central Administration of Statistics (CAS) in partnership with the Palestinian Central Bureau of Statistics (Hass 2017). Nevertheless, it must be noted that an official census has not be conducted in the country since 1932 and the CAS estimate was based on the Palestinian population that lives in the refugee camps only. Additionally, the camps are not exclusively used by Palestinians anymore, as underprivileged Lebanese citizens who cannot afford accommodation in the cities tend to move there as well as various criminals since the Lebanese police rarely enter in the camps. There are manifold political and social reasons to downplay and misconstrue the Palestinian presence in Lebanon, due to their problematic legal status and the complicated sectarian issues in the country.

The international bibliography has dedicated only an exceptionally small fraction dealing with issues related to youth work in Lebanon. Unsurprisingly the vast majority of the literature on the matter examines youth work through the lens of the perennial sectarian issues in the country. Besides, the overwhelming majority of youth work initiatives are linked with the 18 different confessions in the country. ${ }^{1}$ However, it must be noted that even though many civil society efforts regarding youth work are faith-based, it does not mean that they would necessarily exclude young people from different religious backgrounds. Also they all tend to proclaim - even when they are blatantly religiously affiliated, that they operate based on secular criteria. Yet exclusions attributable to religion do happen. Nevertheless, due to confessional enclaves throughout the urban and rural areas it is often unavoidable to observe a concentration of youth workers from a particular religious denomination, even if the $\mathrm{NGO}(\mathrm{s})$ operating in the area are indeed welcoming to all the confessions.

In Lebanon there are more than 6,000 domestic and international active NGOs and according to a report from Beyond Reform and Development (2015: 12), roughly four out of ten of them are related to youth work. Despite overwhelming amount of youth work NGOs operating in such a small country, the state has historically shown a remarkable indifference towards their regulatory framework. It was only after 2000 when youth policies actively started being in the governmental agenda. However, according to Rarrbo (2006) the state maintained a rather lukewarm approach to youth work and policy making. Another report by the Youth Forum for Youth Policy and the Youth Advocacy Process (2012) seems to be on a similar train of thought as it identifies the inadequacies of the Ministry of Youth and Sports regarding youth work and it points out the slow progress of the state to endorse a comprehensive youth policy, while it completely misses to identify the challenges that emerge through the sectarian strife. As Chaaban and Seyfert (2012) mention confessional NGOs have the lion's share in the religiously diverse Lebanon as the volatile political circumstances favour their emergence. However, it has been observed that secondary sources may tend to misrepresent

\footnotetext{
${ }^{1}$ The constitutionally recognised confessions in Lebanon are the following: Shia Muslims (Twelvers, Seveners and Alawites), Sunni Muslims, Maronite Christians, Greek Orthodox Christians, Melkite Christians, Protestants (Seventh Day Adventists and Baptists), Armenian Orthodox or Gregorians, Armenian Catholics, Syrian Catholics, Syrian Orthodox or Jacobites, Roman Catholics, Chaldeans, Copts, Assyrians or Nestorians, Druze and Jewish
} 
the extent of youth work in the country, as they would focus more on specific components and efforts.

For example, a very prominent part of the Lebanese culture related with youth work stems from the various scout organisations. As Lynch (2011) and ShaeryEisenlohr (2011) both recognise that 29 out the 31 scout associations in Lebanon are heavily politicised, the media and scholarly attention is mostly concentrated on the scouts of the Shiite Hezbollah, as it is the largest scout association representing $60 \%$ of all the scouts in the country with its 60.000 young members. Following this particular trend Robert Worth (2008) mentions that the foundations of Hezbollah for devout new generations are built on youth. While Worth's description of Hezbollah's Mahdi Scouts is reminiscent of a football team's youth academy that produces battle-ready recruits instead of athletes, may not be sometimes far from reality, at the same time -in a way- it absolves Amal's Islamic Scout Society or the Future Scouts of Future Movement or the Scouts Chrétiens or the Loving Scouts (an association affiliated with the Frangieh family's militia, the Marada Brigade) from their analogous tendencies as they may also inflame sectarian divisions (Lynch 2011). For these reasons the media in Lebanon, often proclaim as an accusation towards other confessions that the involvement with youth work and the scouts, especially when it is opted for as an escape from the soaring unemployment, maybe a prelude for participation in paramilitary organisations.

However, with the exception of the vehemently injudicious mentions on particular scout associations, since they provide a fertile ground for alarmist headlines in various media outlets, there is no reference in other forms of sports and recreation youth work initiatives in Lebanon, despite many notable results as in the case for example of Chabibeh Youth and Sporting Club in Beirut, a grassroots level youth work organisation that eventually managed with a small budget to send a female basketball team to the first division (Rossis 2015). However, youth work in Lebanon apart from community participation activities that revolve around sports or culture, it is also a significant driving force for vocational training and various initiatives that provide social and health support (Beyond Reform and Development 2015, YAP 2012). Lastly, the very few available secondary sources dedicated to youth work in Lebanon, are also in concordance with the view that youth work is the vanguard for the health sector in the country. But what is that really makes youth work indispensable in Lebanon?

\section{Why Youth Work is so needed?}

Scholars as well as conventional wisdom usually suggest that Lebanon has the remarkable ability to rebuild itself after every major destructive conflict and supposedly rises up from the ashes, as it supposedly happened after the end of the civil war or after the most recent hostilities with Israel in 2006 (Ignatius 1983, Ellis 2002, Ryan 2014). This standpoint, even if it was often conditional, shared a widespread affirmative attitude towards a new era of modernization and restoration; however with the power of hindsight, apart from the soaring debts 
stemming from the various reconstruction loans (Rebuild Lebanon 2007, The Economist(b) 2006, Schenker 2006) and the innate human tendency to move forward after a disastrous event, the infrastructure of Lebanon remains at a significantly low level. With no intention to underestimate the post-conflict efforts to rebuild the country, the infrastructure and the state apparatus plagued by corruption and political instability portray a sub-standard situation, where social welfare and social services are far from being considered as a political priority. According to a Credit Suisse report (2015) the slow, yet increasing, income inequality, coupled with the findings of nationwide study on poverty (Kukrety 2016) suggest that the living standards of the low income households are deteriorating, while unemployment despite the respectable contribution of the informal economy (Rossis 2011), also manifests a slight gradual augmentation (Trading Economics 2017).

Subsequently, civil society efforts are essential in order to fill this social support void. This situation coupled with the significantly young population of the country, frequently renders youth work as the sole refuge for social and health services, employment, vocational training and even basic education.

To be more specific in terms of the educational system, Lebanon has one the highest rates of students attending private schools in the world. $71 \%$ of all the students in Lebanon are enrolled in private schools (54\% to private schools with tuition fees and $17 \%$ to private without tuition fees), while less than one third $(29 \%)$ of the students attend the free public schools (BankMed Special Report 2014). The majority of schools and educational institutes (from kindergarten to university level) in the country have a religious hue, however the drop out levels from the public institutions, according to the BankMed Special Report (2014) chronically maintain an alarming rate of drop-outs. The main reasons behind this phenomenon are associated with the poor standards of the premises, the facilities and the methods of education, as well as with the fact that violence stemming from students (bulling) and teachers is an extremely common occurrence (Hussein 2011). Besides the educators and the parents, according to Article 186 of the Penal Code, are actually by custom permitted to inflict the necessary discipline on the children. Additionally, it has been reported that teachers (due to the extensive moonlighting too) often encourage the pupils to transfer from public to private institutions. Also, in several schools where children of Syrian refugees have enrolled as students, incidents of prejudice and intolerance have also been observed (UNHCR 2015), due to historical enmities and the common perception that underprivileged Lebanese citizens are overlooked in favour of the refugees. As a result manifold NGOs throughout the country persistently provide lifelong learning projects aiming at young male and female adults who have not completed their basic education.

As a logical follow up to basic education, youth work also appears to serve a dual purpose when it comes to the employability of the youth through nonformal education and vocational training. Youth work not only seems to be absorbing some of the excessive overflow of the available young workforce in the country as youth workers, it is also a significant source that invests in the output of skilled employees for the labour intensive industries through a wide 
range of professions like carpenters, hairdressers and other technical occupations. The positive relationship between technical training and the improvement of the living conditions of the undereducated and underprivileged members of the Lebanese society (including refugees) has already been established in a 2008 country study on poverty growth and income distribution (Laithy et al. 2008: 13). The present research obtained limited access to the data of 18 different NGOs related to vocational education that generally correspond with the aforementioned findings. Nevertheless, it was almost impossible and perhaps redundant to quantify or monitor the accomplishments of the vocational training beneficiaries. Through the limited available and reliable information, as the persistent limitations that foster unemployment continue to apply within Lebanon, there is an increased potential for job seeking alternatives in other regional countries and especially the Gulf Cooperation Council countries. The income generated abroad is often translated to remittances. Albeit it is also unfeasible to correlate the proportion of the remittances stemming from the individuals associated with vocational training programmes, according to a Union of Arab Banks report (2016) the remittances flow in Lebanon, without taking into consideration the capital flight through alternative transfer systems like hawala, ${ }^{2}$ represents at least $16 \%$ of the Lebanese GDP. Wwhile vocational training is not entirely neglected by the state-run educational programmes, the cumbersome burden of providing consistent training courses that also adduce realistic prospects and expectations for employment in the future usually falls on the back of the various NGOs operating across the country. Of course, several entanglements related to the cultural and societal complexities emanating from the strong role of religion in the country- especially regarding women and their expected role within the society and the economy- may carry to a certain extent a divisive protocol of training towards a functional all-encompassing and all-inclusive public sphere. Despite the noticeable imbalances, especially from the faith-based NGOS, their impact cannot be underestimated. Additionally, due to their ability to be in synch with the job-related needs at the local level, their vocational training programmes often maintain a marginal superiority over the governmental efforts.

A third aspect of youth work that signifies its vital importance in the country is its contribution to social welfare as youth work, along with the entire NGO sector, is instrumental in offsetting the social services deficit. The state often subcontracts various NGOs in order to provide vital social and health care services. Infrequently, like in the case of Hezbollah for example, the provision of services also extends to infrastructure building such as telecommunications, hospitals and schools, on top of the fact that this particular organisation is the most significant military force in the country. The NGOs in Lebanon often completely substitute the state apparatus, creating a parallel environment of a state-like entity within the actual state. As stated by Wood (Chaaban and Seyfert 2012), the Lebanese state has also been transformed to "a franchise state where the public sector services are dominated by NGO networks". Youth work's dynamism in this instance once again is the motivating force that propels those

${ }^{2}$ Hawala is an informal and highly efficient method of transferring funds without paper trail that is heavily used for remittances transfers. 
endeavours into fruition. The outsourcing of social provisions to domestic, as well as international, NGOs often possesses significant comparative advantages over the national schemes. It was repeatedly observed that the NGOs maintain the necessary wherewithal and know-how in order to provide services up to more than acceptable standards and they facilitate provisions that the state will not defray at all. For example, even the simplest daily chores may be unthinkable for the unemployed or the underprivileged and manifold youth work efforts are dealing with grocery shopping, making arrangements with doctors for the medication of destitute patients and occasionally they even cover medical expenses altogether. Nevertheless, it is the institutionalised part of youth work that composes the most noteworthy undertakings. Youth work in Lebanon is the powerhouse that sustains social support and health care provisions to communities as it also extensively deals with young people with mental disorders and children with special needs in rural areas, as there are no other facilities where issues like these may be dealt with. Despite the overall dependence on youth workers this is a clear indication, as Jawad (2002) has also mentioned by assessing the quality of social welfare through religion in Lebanon that social support and health care services are not rudimentary. Additionally, youth work programmes maintain rehabilitation and day-care centres and they provide for the upkeep of several retirement homes in the country. Another paradigm that displays youth work's value and charitable nature in Lebanon is the humanitarian work, the tutoring and the support it offers to the children of the millions of refugees living throughout the country, as international initiatives and financial support is dwindling. For example, youth workers provide vastly important sanitation and personal hygiene seminars to orphans and long-term displaced minors in various official refugee camps and unofficial "gatherings", as chronically some of them have no proper access to running water and other fundamental utilities. Lastly, several youth work organisations have the capacity to provide financial support and rent stipends, however the reliability and regularity over time may be inconsistent.

The abovementioned features of youth work, although not entirely unique in the wider global context, reflect to the idiosyncrasies of the intricate social web that constitutes the Lebanese general public and to this extend, those features expose sui generis characteristics that make youth work in Lebanon irreplaceable for the foreseeable future. Nevertheless, youth work despite its crucial responsibilities within Lebanon, faces certain challenges that may hinder and obstruct or even threaten its sustainable growth. So what are the predicaments that hold back youth work from realising its full potential in the country and deter it from realising its "tour de force"?

\section{What Makes Youth Work so Convoluted?}

Even during the renowned golden age of Lebanon, when it was dubbed as the Pearl of the Orient, the symbiosis between the multifarious cultural communities was profoundly challenging. The confessional system was meant to be temporary, 
but it became a permanent one as of 1989, when the Taif Agreement reaffirmed citizen representation on the basis of religious sect (Saadeh 2011: 14). The establishment of the confessional system and the subsequent power play between the religiously affiliated parties in the country, along with various domestic and international private initiatives, essentially fuel the manifold and often highly competitive youth work associations throughout Lebanon. As Nelson (2013) mentions this fragile political arrangement, in conjunction with continuous shift in the population affects the elections results to the point that a single party has never obtained the majority of the popular vote. The internal political strife also impinges on the legislative homogeneity in the country (Rossis 2015), as due to the existence of state-sponsored clerical courts which administer family and personal laws, each religious group proffers and endorses dissimilar lawful approaches and interpretations on several legal matters like divorces, inheritances, intermarriages and child custody (Mattar 2017).

As Naufal (2013) mentions youth work is significantly responsible for facilitating most of the humanitarian efforts in Lebanon, but despite its necessity, every new administration due to the sectarian entanglements and the widespread attachment of youth work to different political and religious groups, endorses youth policies that remain lethargic. Interestingly, officials from the Ministry of Youth and Sports have admitted that this monocular situation is perpetuated in order to avoid a disproportional support to organisations with strong sectarian affiliations and in order to prevent particular faith-based NGOs from pursuing their national agendas through youth work. However, the complications that emanate from this situation do not seem to forestall faith-based NGOs -or any other organisation for that matter- from their standard practises.

Nevertheless, another aspect that this research revealed in terms of youth work and the humanitarian aid efforts directed to the millions of refugees is the outspoken reluctance of a small number of organisations (roughly 15\%) from different confessions to extend their services towards the plight of the refugees. While the majority of the respondents' testimonials offered various -sometimes worrisome and sometimes funny- explanations, only one stood out. The rationale behind the reluctance of those youth work NGOs to -even hypotheticallyparticipate in the humanitarian efforts and to support political decisions that favour the abysmal situation of the Palestinian and Syrian refugees is the assertion that the Lebanese citizens have enough problems as it is and they could use all the help available from the government and the international community.

However, as prejudice towards the Palestinian refugees it also reflected on the legal system that prevents them from fully participating in the Lebanese economy (Baraka 2008), the sectarian disputes and animosities amongst the Lebanese citizens, apart from the political arena, also originate from the various cultural identities and values and constitute a major factor that predetermines attitudes. As Harb (2010) mentions in his survey a significant proportion of the Lebanese youth still projects partisan and discriminatory tendencies towards different confessions, as simultaneously a similar percentage displays tolerance and acceptance. However, the most interesting indication for Harb is the significant segment of the youth that displays open-mindedness and approval for the other confessions, 
while it still maintains a safe distance. Interestingly, several of youth workers who participated in the study argue that this is not always necessarily out of conviction and devoutness, but because of their social surroundings, peer pressure and custom. Nevertheless, Pierre Gedeon in his reflection on this particular situation in relation to youth work highlighted that "even 25 years after the end of the civil war students and youth workers may still refuse to visit NGOs in other religious areas" (Rossis 2015)

Another extension of the sectarian feud is associated with the finances of the youth work NGOs and with their donors in particular. Obviously every social welfare effort requires a healthy stream of financial support and the Lebanese state, foreign governments, religious institutions, the sizeable Lebanese Diaspora, the international community, as well as private donors retain the herculean task of youth work in Lebanon. Although many Shia and Sunni youth work NGOs have inadvertently absorbed the burden of the international efforts to tackle the potential of sponsoring organisations related to terrorist activities in light of the war in Syria and subsequently have faced economic drawbacks, Lebanon maintains a delicate, yet spirited, youth work environment. However, there are other relevant issues that more than often appear to hamper manifold youth work activities, due to the lack of reliable oversight and because of the lack of an appropriate regulatory framework that protects the donations as well as the recipients. It has been observed that time and again international and many non-governmental donations are accompanied by specific requests. For example, even secular international NGOs have faced the dilemmas of accepting or not generous donations in order to exclude partners from their activities or to purvey materials and goods only to specific confessions and geographic areas. Also, when donations are administered by governmental agencies it has been reported that the distribution of funds may be unusually delayed or it may be allocated to a completely different organisation or project or even to a completely irrelevant purpose, if not embezzled altogether, as some officials and youth workers claim in their interviews. In light of this, Chaaban and Seyfert (2012) also point out that donors often attempt to promote their ideological preferences and exploit the NGOs in order to gain control over the beneficiaries. As a result of the rampant corruption in aid and donations by the state and particular NGOs the international streams of funding as well as the proposals for new projects are in decline (Akiki 2015).

What is more, as youth work in many areas appears to be the only gateway to a full-time or part-time occupation, youth workers frequently find themselves into an emotionally rewarding working environment due to the nature of their activities. Unfortunately, as the total number of professional youth workers and the volunteer youth workers is totally unknown even to the Lebanese authorities, the harsh working conditions and the long and underpaid working hours with no formal access to social security are quite damaging for the attraction of new volunteers and the preservation of the current number of the skilled professionals in the field. Additionally, there are cases of youth workers from international NGOs facing backlash from their respective communities if their services are not directed to the same confession or if their services are directed towards the Palestinian or Syrian refugees. As rampant unemployment still pushes the younger 
generations to accept less than ideal working conditions and salaries, at the same time the overall frustration of the youth workers produces an environment of ambiguity and unsustainability for the future of youth work.

However, youth work, despite the often uninviting occupational prospects and without access to official data, seems to equally attract women as well as men. Nonetheless, it must be noted, at this point, that women still have a marginal role within the economy (Tailfer 2012). Gender bias is not only visible within the formal and informal employment sector, but also within many youth work activities as several associations (usually faith-based) are actually silent proponents of gender inequality in the working environment. This situation is also reflected in the practices of several organisations due to their selective nature of vocational training and education when is targeted exclusively towards women. However, even when the surroundings and the social context is indeed encouraging enough for women to pursue their careers, the significant lack of social services like day-care, despite the efforts of youth work, may be extremely problematic and subsequently the burden of support returns back to the family ties and kinship to replace the deficiency of social provisions (Tailfer 2012). Also, as Tailfer continues, the omnipresence of sexual harassment is an additional obstacle to women's participation, not only in youth work, but in work in general. Even the field research for this paper, despite the relatively sheltered conditions, has not been immune to inappropriate incidents. Regardless of the cases of unashamed and continuous sexual harassment within many youth work organisations and projects, the respondents without exception agree that women still offer their services in youth work undeterred. The confessional system for Saadeh (2011) is the underlying cause of women's lack of participation in the public sphere, but there are indications now that female empowerment in country is gaining pace. Lebanon displays some progress related to the matter, as the role of women in the country is very slowly advancing, since for the first time ever in 2005 the nation witnessed the appointment of female ministers in the Lebanese Cabinet (Samad, 2008). Also, according to Samad (2008) women have a noticeable and enormous contribution since the 2006 post-war recovery efforts and after 2011 women's massive engagement via numerous NGOs to the humanitarian crisis created by the sudden influx of Syrian refugees in the country is still quite evident, even to the naked eye. Of course, a new draft for youth policies regarding female empowerment and the abolition of the discriminatory laws has been endorsed by the Council of Ministers since 2012 (UNESCO - Youth Forum Lebanon), but with very small actual progress in legislature to this day.

The aforementioned counterproductive elements emanating by the encumbrances of the confessional system and the sectarian polarisation, not only operate as inhibitors for a homogeneous youth work approach in the country but also pose a threat to its sustainability and development. In light of this, the primary source for the necessity of a functional youth work sector practically stems from the very same complications caused by the cultural and political pluralism in the country, which demand more impactful youth work, while obstructing its efficiency and willingness at the same time. 


\section{Conclusion}

Although Lebanon is not typically associated with world hunger, extreme poverty and reliance on humanitarian aid for the survival of parts of its population, the country's present conditions are applicable to the aforementioned issues. Apparently, the reasons that hoist the necessity of youth work are not exclusively applicable in the Lebanese context; nevertheless it became evident that without it, the living standards and the bare minimum of many constitutionally vested social amenities for a considerable segment of the public cannot be safeguarded by the state.

In the two years following the developments on the youth work front in Lebanon, it has been observed that the duties bestowed on youth work by the state or by the civil society itself due to the complete lack of social services in certain areas, have not been alleviated by any political decisions and youth still represents the delicate backbone of social support. The political landscape during the research has been typically complicated due the drawn out presidential vacuum constantly dominating the political agenda and youth work despite setbacks related to corruption the sectarian antagonism and the hesitant adoption of impactful youth policies, thanks to the persistence of the civil society has moved slightly forward.

In 2015 for example, there were only 8 NGOs accredited with the European Voluntary Service since its inception by the European Commission. By 2017, this number had been increased to the total of 19 organisations accredited to run projects under the European Voluntary Service which is part of the European Union's Erasmus+ programme, indicating the significantly augmented capabilities for networking of the Lebanese youth work environment. In the duration of the two years observing and following youth work in Lebanon the manifold elements that render it indispensable in the country remain generally unaffected, despite the existence of circumstantial shifting trends and variables that may have been taken into consideration. In the meanwhile the intrinsic aspects that persistently deject youth work also remain impervious to change. Youth work for Lebanon is the ultimate nexus that through a unique sense of balance bridges the usual community support activities with humanitarian relief. As Jawad (2002) proposes social welfare in Lebanon -and consequently youth work as well- are primarily charitable initiatives that spring mainly from the private sphere, but once they assume a public role they also become politicized. And for this reason youth work may be carrier of tolerance and hope and at the same time it may be a partisan of sectarian conflict.

Be that as it may, youth work in Lebanon grows. But if youth work will eventually become an exclusive tool for political interests, geared up to implode under the weight of the aforementioned duties and complications or if it will become a dynamic force of social support by bonding all the various confessions and identities together, it is the foundation of another scholarly analysis. 


\section{References}

Akiki V (2015) Corruption creeps into refugee aid in Lebanon. Retrieved from https://bit. ly/1FrIsCi. [Accessed 16 August 2017].

BankMed Special Report (2014) Analysis of Lebanon's Education Sector. BankMed Market And Economic Research Division.

Baraka H (2008) Palestinians in Lebanon: Chains of Misery (Bound by the Law and the Market). FMRS Working Paper 9.

Beyond Reform and Development (2015) Mapping Out Civil Society Organisations in Lebanon. Beirut: Civil Society Facilty South, Beyond Reform and Development.

Chaaban J Seyfert K (2012) Faith-based NGOs Iin A Multi-Confessional Society: Evidence From Lebanon. Doha: Arab Center For Research And Policy Studies.

Credit Suisse (2015) Global Wealth Databook 2014. Retrieved from https://bit.ly/ 2NFnnNh.

Ellis K (2002) Lebanon's Second Republic: Prospects for the Twenty-first Century. Gainesville: University Press of Florida.

Harb C (2010) Describing the Lebanese Youth: A National and Psycho-Social Survey. Beirut: The Issam Fares Institute for Public Policy and International Affairs \& AUB.

Hass A (2017) Lebanon Census Finds Number of Palestinian Refugees Only a Third of Official UN Data. Retrieved from https://bit.ly/2N4Eg39. [Accessed 2 April 2018].

Hussein L H (2011) An exploration into senior and middle managers' effectiveness : The Education Programme, United Nations Relief and Works Agency (UNRWA) for Palestine Refugees, Lebanon. Bradford: University Of Bradfor.

Ignatius D (1983) Rebuilding Lebanon. Foreign Affairs 61(5): 1140-1156.

Jawad R (2002) A Profile of Social Welfare in Lebanon: Assessing the Implications for Social Development. Global Social Policy 2(3): 319-342.

Kukrety N (2016) Poverty, Inequality and Social Protection in Lebanon. Oxfam American University of Beirut. Retrieved from https://bit.ly/2u76EdP.

Laithy H, Abu-Ismail K, Hamdan K (2008) Poverty, Growth and Income Distribution in Lebanon, Country Study No 13 ed. Brasilia: International Poverty Centre. Retrieved from https://bit.ly/2NFEHSs.

Lynch S (2011) Lebanon's scout promise. Retrieved from https://bit.ly/2KLor4v. [Accessed 18 September 2015].

Mattar S (2017) Family Law in Lebanon. Retrieved from https://bit.ly/2N4zfHL [15 August 2017].

Naufal H (2013) Syrian Refugees in Lebanon: the Humanitarian Approach Under Political Divisions. Florence: European University Institute, Migration Policy Center.

Nelson S (2013) Is Lebanon's confessional system sustainable? Journal of Politics \& International Studies 9: 332-387.

Rarrbo K (2006) Studies On Youth Policies In The Mediterranean Partner Countries: Lebanon. EuroMed Youth III Programme.

Rebuild Lebanon (2007) IMF approves $\$ 77$ million loan to rebuild Lebanon. Retrieved from https://bit.ly/2ullgpf [06 August 2017].

Rigby A (2000) Lebanon: patterns of confessional politics. Parliamentary Affairs 53(1): $169-180$.

Rossis N (2011) The Informal Economy in Lebanon: Dangers and Benefits. Doctoral thesis, Durham University. Retrieved from https://bit.ly/2N2ztin.

Rossis N (2015) Youth Work in Lebanon and Cultural Identities: "Diversity of Communities: Richness or...?". INJEP.

Ryan A (2014) Rebuilding Beirut: From Ruin to Simulacrum. Interventions Journal 3 (3: 
Vol. 4, No. 3 Rossis: The Indispensability and the Perplexities of Youth Work in the...

The Rhetoric of Memory). Retrieved from https://bit.ly/2NF0J7Z.

Saadeh S (2011) Women in Lebanese Politics: Underlying Causes of Women's Lack of Representation in Lebanese Politics. In Emerging Voices: Young Women in Lebanese Politics, 14-15. International Alert. Retrieved from https://bit.ly/2NDsrSw.

Samad ZA (2008) Millennium Development Goals: Lebanon Report 2008. United Nations Development Programme. Retrieved from https://bit.ly/2G9wbrC.

Schenker D (2006) Reconstructing Lebanon: Short- and Longer-Term Challenge (Policy Analysis). The Washington Institute (PolicyWatch 1146). Retrieved from https://bit. ly/2KYNIaF. [Accessed 10 August 2017].

Shaery-Eisenlohr R (2011) Shi'ite Lebanon: Transnational Religion and the Making of National Identities. New York: Columbia University Press.

Tailfer DT (2012) Women and Economic Power In Lebanon: The legal framework and challenges to women's economic empowerment. Beirut: Collective for Research and Training in Development.

The Economist (2016) Lebanon: Census and Sensibility. Retrieved from https://econ. st/2vTYnfi.

The Economist (2006b) Lebanon's economy: Debt and Destruction. The Economist. Retrieved from https://econ.st/2zwxh0C. [Accessed 8 August 2017].

Trading Economics (2017) Lebanon Unemployment Rate 1991-2017. Trading Economics. Retrieved from https://bit.ly/2hQCRjv. [15 August 2017].

UNESCO - Youth Forum Lebanon (2012) Youth Policy in Lebanon (Endorsed on 3rd April 2012). Beirut: SIDA - UNESCO - Youth Frrum.

UNHCR (2015) The Future Of Syria: The Challenge Of Education. Retrieved from https://bit.ly/1vlHdRz [Accessed 17 September 2015].

UNHCR (2016) The Situation of Palestinian Refugees in Lebanon. UN Refugee Agency. Retrieved from https://bit.ly/2mXsqOg.

Union of Arab Banks (2016) Remittances to the Arab Region: Economic, Financial, and Developmental Impact. Union of Arab Banks Research Department. Retrieved from https://bit.ly/2KMnqsO.

United Nations (2017) World Population Prospects: The 2017 Revision. UN - Department of Economic and Social Affairs - Population Division.

Wickberg S (2012) Overview of corruption and anti-corruption in Lebanon. Transparency International and U4 - Anticorruption Resource Centre. Retrieved from https://bit. ly/2N3BUkY.

Worth RF (2008) Hezbollah's foundation is built on youth. New York Times. Retrieved from: https://nyti.ms/2ulx8aL. [Accessed 9 August 2017].

YAP (2012) The Youth Policy in Lebanon (Case Study). Beirut: Youth Forum For Youth Policy - Youth Advocacy Process. 